\title{
Bacteriological evidence of antibiotic failure in pneumococcal lower respiratory tract infections
}

\author{
K.P. Klugman
}

\begin{abstract}
Bacteriological evidence of antibiotic failure in pneumococcal lower respiratory tract infections. K.P. Klugman. (C) ERS Journals Ltd 2002.

ABSTRACT: The global pandemic of antimicrobial resistance, particularly in the pneumococcus, has had a major impact on the management of community-acquired pneumonia.

A number of prospective and retrospective studies have analysed the impact of penicillin resistance on clinical outcome in pneumonia. Pharmacodynamic principles predicting success when the antibiotic dose exceeds the minimum inhibitory concentration (MIC) for $\mathbf{4 0 - 5 0 \%}$ of the dosing interval have proved remarkably accurate. There is no evidence of bacteriological failure of penicillins active against resistant strains. There is a single report of the failure of the less active agent, ticarcillin. High dose oral and intravenous amoxicillin should treat strains with MICs $\leqslant 4 \mu \mathrm{g} \cdot \mathrm{mL}^{-1}$, as should high doses of intravenous penicillin, ceftriaxone and cefotaxime. Strains of pneumococci resistant to these agents at an MIC $\geqslant 8 \mu \mathrm{g} \cdot \mathrm{mL}^{-1}$ are rare at the present time. Most other cephalosporins are less active and should not be used empirically for drug-resistant Streptococcus pneumoniae. Bacteriological failures of cefazolin, cefuroxime and ceftazidime have been reported.

There is increasing evidence of bacteriologically confirmed macrolide failure of pneumonia therapy at MICs $\geqslant 4 \mu \mathrm{g} \cdot \mathrm{mL}^{-1}$. The molecular basis of the resistance is irrelevant if the MIC is in that range or higher. Double mutants in the parC and $\operatorname{gyr} A$ genes lead to fluoroquinolone resistance that has been found to cause bacteriological failure of the fluoroquinolones, particularly levofloxacin and ciprofloxacin, in the management of pneumonia and exacerbations of chronic bronchitis. Two mutations in these genes can greatly increase the MICs of all the marketed fluoroquinolones, and raise the prospect of failure of therapy even with the more active ones. However, demonstration of bacteriological failure of gatifloxacin or moxifloxicin has not yet been reported.

High dose, active $\beta$-lactams or fluoroquinolones with enhanced activity against Gram positive pathogens remain the drugs of choice for the management of communityacquired pneumonia caused by the drug-resistant pneumococcus.

Eur Respir J 2002; 20: Suppl. 36, 3s-8s.
\end{abstract}

Low levels of penicillin resistance in the pneumococcus were first described in Australia during the 1960s [1], and multiple and high-level resistance (defined as a penicillin minimum inhibitory concentration (MIC) $\geqslant 2 \mu \mathrm{g} \cdot \mathrm{mL}^{-1}$ ) were first described in South Africa in the 1970s [2,3]. At that time, it was widely assumed that there was a direct relationship between in vitro resistance and clinical failure. Indeed, a number of reports, for example that by FELDMAN et al. [4], documented the failure of therapy associated with mortality in adults with pneumonia, infected with penicillinresistant strains. However, it has been apparent for the past 40 yrs that there is $5 \%$ mortality in bacteremic pneumococcal pneumonia that has not been altered by appropriate antimicrobial therapy [5]. These data date back from the days when there were no resistant pneumococci described. Therefore, the concordance, of clinical failure and antibiotic resistance will occur by chance in $5 \%$ of patients infected with antibioticresistant pneumococci. Any analysis of the impact of
Correspondence: K.P. Klugman Dept of International Health Rollins School of Public Health

Room 764

Emory University

1518 Clifton Rd NE

Atlanta

Georgia 30322

USA

Fax: 14047274590

E-mail:kklugma@sph.emory.edu

Keywords: Antimicrobial resistance fluoroquinolones

macrolides

penicillin

pneumonia

Streptococcus pneumoniae

Received: January 312002

Accepted after revision: March 42002 resistance on outcome needs to be stratified for confounding variables, such as an association between resistance and severity of disease. As resistant strains are commonly associated with hospitals and nosocomial infections [6], there is a greater chance of immunocompromised patients being infected with resistant strains $[7,8]$. The most important predictor of outcome in pneumonia is severity of disease, and it is therefore critical to the analysis of outcome to stratify cases for severity of disease [9]. It is also essential that careful information is obtained about the exact dose and duration of antimicrobial received before failure is documented. The best indicator of the failure of an antibiotic is the persistent presence of bacteria. This is difficult to document in the majority of patients with pneumonia. Persistent presence of bacteria in purulent sputum is highly suggestive of bacteriological failure, but may be confounded by the contamination of sputum with saliva and the detection of colonising rather than pathogenic strains. Persistent bacteremia 
is unequivocal proof of bacteriological failure, but repeated blood cultures are seldom taken once therapy has been commenced. The bacteriological documentation of failure has therefore rarely been proven. This review will describe the principles of the pharmacodynamics of treatment of pneumococcal pneumonia and will discuss the various studies performed to date, describing the failure, or lack there of, of various classes of antimicrobials for the management of pneumococcal pneumonia.

\section{$\beta$-lactam agents}

An analysis of early reports of penicillin failure in the management of pneumococcal pneumonia revealed no bacteriological evidence of the failure of penicillin in this therapeutic setting [10]. A large prospective series of patients from Spain showed no difference in the 30-day mortality of patients treated with $\beta$-lactam agents, when patients infected with strains resistant to penicillin were compared with patients infected with susceptible bacteria [11]. Although the failure of two patients with the most highly penicillin-resistant strains was described, the only documented bacteriological failure occurred in a patient treated with ticarcillin, for which the MIC was $64 \mu \mathrm{g} \cdot \mathrm{mL}^{-1}$. There was no bacteriological evidence of penicillin failure. Similar conclusions were reached in a retrospective study of nonmeningeal pneumococcal bacteremia in children in South Africa [12]. There was no difference in mortality between children infected with penicillinresistant strains and those infected with susceptible strains. All children were treated with either intravenous ampicillin or penicillin, and a subsequent analysis revealed no difference in the time to resolution of symptoms or any other measure of morbidity between the two groups [13]. The majority of infections in both of these studies were intermediately resistant to penicillin $[11,12]$.

The pharmacokinetics of penicillin in serum have recently been reviewed by BRYAN et al. [14]. These data suggest that if a penicillin drug level exceeding the MIC of a resistant bacterium is required for $40 \%$ of the dosing interval, a penicillin dose of 2,000,000 units may be given 4-hourly to treat a highly resistant pneumococcus with an MIC of $\leqslant 4 \mu \mathrm{g} \cdot \mathrm{mL}^{-1}$ [15]. The same dose should be effective even if it is administered 6-hourly. Therefore, it may be concluded from pharmacodynamic principles that daily doses of intravenous penicillin in the range of 8-12 million units $\cdot$ day $^{-1}$ should treat even highly-resistant pneumococcal infections.

\section{Bacteriological evidence of the failure of $\beta$-lactam therapy in pneumonia}

There are a number of reports on the failures of $\beta$-lactam agents for the management of penicillinresistant pneumonia (table 1). The agents that failed are, in general, agents with less activity against the pneumococcus than penicillin or amoxicillin. Indeed, there are no reports of the bacteriological failure of either penicillin or amoxicillin, or of highly active agents such as the carbapenems, imipenem, or meropenem. Amongst the penicillins, the only case of bacteriological failure was the case previously described, of a patient treated with ticarcillin against a ticarcillin-resistant strain (MIC $64 \mu \mathrm{g} \cdot \mathrm{mL}^{-1}$ ) [11]. The bacteriological failure of cefazolin, a first-generation cephalosporin, as well as the second-generation cephalosporin, cefuroxime, and the poorly active thirdgeneration cephalosporin, ceftazidime, have all been described previously [16-19]. There is a single case report of a bacteriological failure of low dose cefotaxime $\left(100 \mathrm{mg} \cdot \mathrm{kg}^{-1} \cdot \mathrm{day}^{-1}\right)$ plus gentamicin in a patient with a bacteremia caused by a highly resistant (cefotaxime MIC $6 \mu \mathrm{g} \cdot \mathrm{mL}^{-1}$ ) pneumococcus [20]. This patient developed meningitis and the failure may have been due to seeding of organisms from the meninges to the blood.

\section{Retrospective studies of $\beta$-lactam therapy for pneumonia}

TuretT et al. [21] described an independent association of pneumococci with penicillin MICs of $\geqslant 2 \mu \mathrm{g} \cdot \mathrm{mL}^{-1}$ and mortality. This study did not adjust for severity of disease, and $50 \%$ of the patients were HIV infected. Indeed, only two patients in the study received penicillin. One patient infected with an intermediately resistant strain responded to oral amoxicillin, and the second patient, who was severely ill, infected with a highly-resistant strain, died after only a single dose of ticarcillin. This study therefore provides little evidence of the failure of $\beta$-lactam agents in the management of penicillin-resistant pneumococcal pneumonia.

Table 1.-Bacteriological failures of $\beta$-lactam therapy of respiratory tract infections caused by drug-resistant pneumococci

\begin{tabular}{|c|c|c|c|c|}
\hline Therapeutic agent & Other drugs given & $\begin{array}{l}\text { Site of growth of } \\
\text { resistant bacterium }\end{array}$ & $\begin{array}{l}\text { MIC of resistant } \\
\text { bacterium } \mu \mathrm{g} \cdot \mathrm{mL}^{-1}\end{array}$ & Ref. \\
\hline Ticarcillin & & Blood & 64 & {$[11]$} \\
\hline Cefazolin & Gentamicin & Blood & 8 & [16] \\
\hline Cefuroxime & $\begin{array}{l}\text { Clarithromycin } \\
\text { Cefotaxime }\end{array}$ & Blood/CSF & 8 & [17] \\
\hline Cefuroxime & $\begin{array}{l}\text { Cefuroxime axetil } \\
\text { Ceftriaxone } \\
\text { Ceftibuten }\end{array}$ & Blood & 8 & {$[18]$} \\
\hline Ceftazidime & Gentamicin & Blood & 32 & [19] \\
\hline
\end{tabular}

MIC: minimum inhibitory concentration; CSF: cerebrospinal fluid. 
A retrospective analysis by FEIKEN et al. [22] revealed an intriguing association of late mortality (deaths after 4 days of therapy) in patients infected with pneumococci highly resistant to penicillin (MIC $\left.\geqslant 4 \mu \mathrm{g} \cdot \mathrm{mL}^{-1}\right)$. The odds ratio for mortality was 7.1 with a $95 \%$ confidence interval of $1.7-30$. In the study, there was no association between penicillin MICs $\leqslant 2 \mu \mathrm{g} \cdot \mathrm{mL}^{-1}$ and mortality. While the late mortality may be suggestive of a true association between resistance and poor outcome, the authors were unable to stratify the data for severity of disease. It is also important to note that no information on antibiotic therapy was available to the authors, so that any association of resistance with mortality could not be related to the failure of specific antimicrobial agents [22]. In a retrospective chart review of 44 patients with penicillin nonsusceptible pneumococci (most of which were intermediate resistant), Metlay et al. [23] were unable to find an association of poor outcome with resistance once they controlled for severity of disease. The study did document an excess of suppurative complications (empyema); 2\% (3 of 142) in patients infected with susceptible strains versus $9 \%$ (4 of 44 ) in patients with resistant strains. These data [20] suggest that resistant strains may be clinically nonresponsive to therapy in the setting of an empyema, an observation consistent with pharmacodynamic theory. MORONEY et al. [24] failed to find an association between cephalosporin strains with MICs $\geqslant 2$ and mortality. Poor outcome was related to severity of disease. A study in children in Uruguay, including a large number of children infected with highly penicillin-resistant strains, documented a failure rate based on clinical observation of $22 \%$ (5 of 23 ) in patients infected with the highly penicillin-resistant pneumococci [25]. This failure rate was high, but less than the $30 \%$ failure rate (17 of 52) found in patients infected with penicillin-susceptible Streptococcus pneumoniae. This study is important because the therapeutic choice was largely uninfluenced by the susceptibility results, as the susceptibility testing was performed on strains sent to Canada and the analysis of outcome was performed by an observer blinded to the resistance status of the pathogen. A recent analysis of 522 bacteremic episodes has documented no difference of 30-day mortality between patients infected with resistant and susceptible strains. The patients treated with penicillin or amoxicillin and infected with highly resistant strains had a 30 -day mortality of $17 \%$ compared to $27 \%$ mortality in patients treated with intermediately resistant strains. A similar trend was observed in patients treated with cefotaxime or ceftriaxone, with $11 \%$ mortality amongst those infected with highly penicillin-resistant strains and $21 \%$ mortality in those with intermediately resistant strains [26]. These data suggest the possibility that more highly resistant strains may be less virulent. There are some data on experimental pneumonia in animals that support this contention [27].

\section{Macrolides}

In contrast to the lack of evidence of bacteriological failure in patients treated with active $\beta$-lactam drugs, there are now numerous case reports with bacteriological evidence of macrolide failure in patients infected with macrolide-resistant pneumococci (table 2). The following reports describe the culture from blood, or other sterile sites, of macrolide-resistant pneumococci from both children and adults receiving macrolide drugs. The first report was of a 2-yr-old male who developed pneumonia while receiving erythromycin. A pneumococcus with an erythromycin MIC of $>8 \mu \mathrm{g} \cdot \mathrm{mL}^{-1}$ was isolated from the patient's blood [28]. Two adults taking erythromycin with worsening pneumonia had lung aspirates that grew pneumococci and MICs of $>8 \mu \mathrm{g} \cdot \mathrm{mL}^{-1}$ [29]. A $32 \mathrm{yr}$ old worsened on erythromycin therapy and the blood grew a pneumococcus with an MIC of $64 \mu \mathrm{g} \cdot \mathrm{mL}^{-1}$ [30]. A 49 -yr-old female deteriorated on azithromycin therapy and died despite addition of levofloxacin and vancomycin. A pneumococcus with an MIC of $16 \mu \mathrm{g} \cdot \mathrm{mL}^{-1}$ grew from her blood [31]. Three patients being treated with azithromycin had pneumococci isolated from their blood. Their MICs were 8,8 , and $>128 \mu \mathrm{g} \cdot \mathrm{mL}^{-1}$, respectively [32]. Four patients, including one child, receiving azithromycin [3] or clarithromycin [1] had pneumococci isolated from their blood while they were receiving the drugs. Their erythromycin MICs were $8,16,16$, and $8 \mu \mathrm{g} \cdot \mathrm{mL}^{-1}$, respectively [33]. GARAU [34] has recently described a series of both adults and children in whom macrolide-resistant pneumococci were grown from blood while they were receiving macrolides or azithromycin therapy [34]. An analysis of these failures documents a threshold for bacteriological failure of $\sim 8 \mu \mathrm{g} \cdot \mathrm{mL}^{-1}$, a level unachievable for $50 \%$ of the dosing interval in patients treated with intravenous erythromycin. There has been some speculation as to whether the mechanism of macrolide resistance may lead to different outcomes in the management of macrolide-resistant pneumococcal pneumonia. Resistance mediated by the ermB gene leads to macrolide MICs usually in the range of $>32 \mu \mathrm{g} \cdot \mathrm{mL}^{-1}$, while macrolide resistance due to the $m e f A$ gene leads to variable expression of macrolide resistance in the range of $1-64 \mu \mathrm{g} \cdot \mathrm{mL}^{-1}$. Recently, strains have been described that harbor both macrolide resistance mechanisms [35]. These strains are highly resistant to the macrolides (MICs of $128 \mu \mathrm{g} \cdot \mathrm{mL}^{-1}$ ). As there have been bacteriologically documented failures in patients infected with pneumococci expressing mef $A$ resistance when the MIC is $\geqslant 8 \mu \mathrm{g} \cdot \mathrm{mL}^{-1}$ [34], the level of MIC is, therefore, a more important predictor of the clinical relevance of macrolide resistance than is the presence of the $m e f A$ gene.

\section{Trimethoprim-sulphamethoxazole}

While this agent is rarely used for the management of pneumonia in developed countries, it remains the recommended drug of choice for the management of pneumonia in children in developing countries. This recommendation is based on the low cost of the agent and its activity against malaria in malaria endemic areas where the differential diagnosis of a child with pneumonia includes infection with Plasmodium sp. There are no data on the clinical relevance of 
Table 2.-Bacteriological failures of macrolide therapy of respiratory tract infections caused by drug-resistant pneumococci

\begin{tabular}{|c|c|c|c|c|}
\hline Therapeutic agent & Other drugs given & $\begin{array}{l}\text { Site of growth of } \\
\text { resistant bacterium }\end{array}$ & $\begin{array}{l}\text { MIC of resistant } \\
\text { bacterium } \mu \mathrm{g} \cdot \mathrm{mL}^{-1}\end{array}$ & Ref. \\
\hline Erythromycin & & Blood & $>8$ & {$[28]$} \\
\hline Erythromycin & & Lung puncture & $>8$ & [29] \\
\hline Erythromycin & & Lung puncture & $>8$ & [29] \\
\hline Erythromycin & & Blood & $>8$ & [30] \\
\hline Erythromycin & & Blood & $>8$ & [34] \\
\hline Erythromycin & & Blood & $>8$ & [34] \\
\hline Erythromycin & & Blood & $>8$ & [34] \\
\hline Azithromycin & $\begin{array}{l}\text { Levofloxacin } \\
\text { Vancomycin }\end{array}$ & Blood & 16 & [31] \\
\hline Azithromycin & & Blood & 8 & {$[32]$} \\
\hline Azithromycin & & Blood & 8 & [32] \\
\hline Azithromycin & & Blood & $>128$ & [32] \\
\hline Azithromycin & & Blood & 8 & [33] \\
\hline Azithromycin & & Blood & 16 & [33] \\
\hline Azithromycin & & Blood & 16 & [33] \\
\hline Azithromycin & & Blood & $>8$ & [34] \\
\hline Azithromycin & & Blood & $>8$ & [34] \\
\hline Azithromycin & & Blood & $>8$ & [34] \\
\hline Azithromycin & & Blood & $>8$ & [34] \\
\hline Clarithromycin & & Blood & 8 & [33] \\
\hline Clarithromycin & & Blood & $>8$ & [34] \\
\hline Clarithromycin & & Blood & $>8$ & [34] \\
\hline Clarithromycin & & Blood & $>8$ & [34] \\
\hline Josamycin & & Blood & $>8$ & [34] \\
\hline Josamycin & & Blood & $>8$ & {$[34]$} \\
\hline
\end{tabular}

MIC: minimum inhibitory concentration. ${ }^{\#}$ : failed salvage therapy.

trimethoprim-sulphamethoxazole resistance for the management of pneumonia, although there are reports of the bacteriological failure of this agent in the management of pneumonia [28]. A randomised trial of trimethoprim-sulphamethoxazole versus amoxicillin in the management of pneumonia in Pakistan revealed a poorer outcome in the group receiving trimethoprimsulphamethoxazole [36]. Although there was a high rate of resistance to this agent in the study, no consistent association of poor outcome with MIC could be established. Some data suggest that breakthrough bacteremias occur in human immunodeficiency virus (HIV)-infected patients receiving trimethoprimsulphamethoxazole prophylaxis [37]. More data are required to document the impact of resistance to this agent on outcome, especially since widespread use of this agent may be expected in resource-poor countries in an attempt to prevent morbidity and mortality in HIV-infected adults and children, in the absence of therapy with effective antiretroviral agents.

\section{Fluoroquinolones}

There are bacteriologically confirmed failures of ciprofloxacin and, more recently, of levofloxacin, in the management of pneumococcal pneumonia, sinusitis, bronchitis, and exacerbation of chronic bronchitis (table 3) [38-43]. The pharmacodynamics of ciprofloxacin suggest that strains of pneumococci may not respond to therapy, even in the absence of resistance mutations. Once this and other fluoroquinolones,

Table 3.-Bacteriological failure of fluoroquinolone therapy of respiratory tract infections caused by drug-resistant pneumococci

\begin{tabular}{|c|c|c|c|c|c|}
\hline Therapeutic agent & Initial infection & Other drugs given & $\begin{array}{l}\text { Site of growth of } \\
\text { resistant bacterium }\end{array}$ & $\begin{array}{l}\text { MIC of resistant } \\
\text { bacterium } \mu \mathrm{g} \cdot \mathrm{mL}^{-1}\end{array}$ & Ref. \\
\hline Ciprofloxacin & Pneumonia & & Empyema & 4 & {$[38]$} \\
\hline Ciprofloxacin & AECB & & Sputum & $\geqslant 8$ & [42] \\
\hline Levofloxacin & Pneumonia & & Sputum & 8 & {$[40]$} \\
\hline Levofloxacin & Pneumonia & & Sputum & 16 & {$[40]$} \\
\hline Levofloxacin & AECB & & Sputum & $>32$ & [39] \\
\hline Levofloxacin & Bronchitis & & Sputum & $>32$ & [41] \\
\hline Levofloxacin & Pneumonia & & Sputum & 6 & [43] \\
\hline Levofloxacin $\#$ & Pneumonia & & Sputum & $\geqslant 8$ & [42] \\
\hline Levofloxacin ${ }^{\#}$ & AECB & & Sputum & $\geqslant 8$ & {$[42]$} \\
\hline
\end{tabular}

MIC: minimum inhibitory concentration; AECB: acute exacerbation of chronic bronchitis. ${ }^{\#}$ : low dose $400 \mathrm{mg} \cdot \mathrm{day}^{-1}$. 
which are less active against the pneumococcus, have selected mutations in the parC or gyr $A$ genes, therapy with pharmacodynamically more active agents such as levofloxacin may also fail. Indeed, the activity of levofloxacin against the pneumococcus is such that two mutations can lead to bacteriologically confirmed failures in patients infected with strains having MICs of $\geqslant 32 \mu \mathrm{g} \cdot \mathrm{mL}^{-1}$. Two patients developed increasing resistance (MICs increasing from susceptible to 8 and from 4 to $16 \mathrm{mg} \cdot \mathrm{mL}^{-1}$ ) to levofloxacin in isogenic strains from sputum, associated with treatment failure [40]. Seven further patients treated with ciprofloxacin or levofloxacin for pneumonia or exacerbations of chronic bronchitis failed clinically and had resistant strains isolated on therapy from the sputum $[38,39$, 41-43].

At the present time, there is emerging fluoroquinolone resistance in Hong Kong, associated with widespread use of these agents for the management of pneumonia [44]. Although more active agents, such as gatifloxacin and moxifloxicin, may be used for the management of pneumonia, it is concerning that widespread use of less active fluoroquinolones for the treatment of pneumonia is confering resistance to the entire class of agents. To date, there have been no bacteriologically confirmed cases of failure of gatifloxacin or moxifloxicin in the management of pneumonia.

\section{Other drugs}

The failures of other drugs, such as the tetracyclines, streptogramins and rifamycins, have been documented when attempts were made to treat strains with MICs in excess of achievable blood levels [8, 10].

\section{Conclusion}

The global dissemination of antimicrobial resistance in the pneumococcus has lead to a number of therapeutic dilemmas in the management of pneumococcal pneumonia. Available evidence suggests that highly-active $\beta$-lactam agents, such as penicillin, amoxicillin, the extended-spectrum cephalosporins, cefotaxime or ceftriaxone, and the carbapenems, meropenem and imipenem, all retain useful clinical activity for the treatment of pneumococcal pneumonia. The vast majority of patients infected with penicillinresistant pneumococci can be expected to respond to empirical therapy with these agents. Although no pneumococci resistant to vancomycin have been described, this agent should be reserved for combination therapy of meningitis, and there are few indications for its use in the management of pneumococcal pneumonia at this time. Patients not responsive to active $\beta$-lactam agents may be treated with fluoroquinolones with enhanced activity against the pneumococcus, such as gatifloxacin or moxifloxacin. While the macrolides have a clear role in combination empirical therapy of pneumonia, the widespread prevalence of macrolide resistance in the pneumococcus makes it difficult to justify empirical monotherapy with a macrolide. Empirical therapy of pneumonia with trimethoprim-sulphamethoxazole cannot be justified unless there are compelling financial reasons for its use. Pharmacodynamic principles have allowed the development of rational guidelines for the treatment of pneumonia. Optimal therapy depends on the selection of agents that are reliably able to kill pneumococci, even in an environment in which antibiotic-resistant strains are common.

\section{References}

1. Hansman D, Bullen M. A resistant pneumococcus. Lancet 1967; ii: 264-265.

2. Jacobs MR, Koornhof HJ, Robins-Browne RM, et al. Emergence of multiply resistant pneumococci. New Engl J Med 1978; 299: 735-740.

3. Appelbaum PC, Bhamjee A, Scragg JN, Hallett AF, Bowen AJ, Cooper RC. Streptococcus pneumoniae resistant to penicillin and chloramphenicol. Lancet 1977; 2: 995-997.

4. Feldman C, Kallenbach JM, Miller SD, Thorburn JR, Koornhof HJ. Community-acquired pneumonia due to penicillin-resistant pneumococci. New Engl J Med 1985; 313: 615-617.

5. Austrian R, Gold J. Pneumococcal bacteremia with especial reference to bacteremic pneumococcal pneumonia. Ann Intern Med 1964; 60: 759-776.

6. Bedos JP, Chevret S, Chastang C, Geslin P, Regnier B. Epidemiological features of and risk factors for infection by Streptococcus pneumoniae strains with diminished susceptibility to penicillin: findings of a French survey. Clin Infect Dis 1996; 22: 63-72.

7. Crewe-Brown HH, Karstaedt AS, Saunders GL, et al. Streptococcus pneumoniae blood culture isolates from patients with and without human immunodeficiency virus infection: alterations in penicillin susceptibilities and in serogroups or serotypes. Clin Infect Dis 1997; 25: 1165-1172.

8. Klugman KP. Pneumococcal resistance to antibiotics. Clin Microbiol Rev 1990; 3: 171-196.

9. Fine MJ, Smith MA, Carson CA, et al. Prognosis and outcomes of patients with community-acquired pneumonia. A meta-analysis. JAMA 1996; 275: 134 141.

10. Klugman KP. The clinical relevance of in vitro resistance to penicillin, ampicillin, amoxycillin and alternative agents, for the treatment of community-acquired pneumonia caused by Streptococcus pneumoniae, Haemophilus influenzae and Moraxella catarrhalis. J Antimicrob Chemother 1996; 38: Suppl. A, 133-140.

11. Pallares R, Linares $\mathrm{J}$, Vadillo $\mathrm{M}$, et al. Resistance to penicillin and cephalosporin and mortality from severe pneumococcal pneumonia in Barcelona, Spain. New Engl J Med 1995; 333: 474-480.

12. Friedland IR, Klugman KP. Antibiotic-resistant pneumococcal disease in South African children. $\mathrm{Am}$ J Dis Child 1992; 146: 920-923.

13. Friedland IR. Comparison of the response to antimicrobial therapy of penicillin-resistant and penicillinsusceptible pneumococcal disease. Pediatr Infect Dis $J$ 1995; 14: 885-890.

14. Bryan CS, Talwani R, Stinson MS. Penicillin dosing for pneumococcal pneumonia. Chest 1997; 112: 16571664. 
15. Craig WA. Pharmacokinetic/pharmacodynamic parameters: rationale for antibacterial dosing of mice and men. Clin Infect Dis 1998; 26: 1-10.

16. Sacho H, Klugman KP, Koornhof HJ, Ruff P. Community-acquired pneumonia in an adult due to a multiply-resistant pneumococcus. J Infect 1987; 14: 188-189.

17. Buckingham SC, Brown SP, Joaquin VH. Breakthrough bacteremia and meningitis during treatment with cephalosporins parenterally for pneumococcal pneumonia. J Pediatr 1998; 132: 174-176.

18. Dowell SF, Smith T, Leversedge K, Snitzer J. Failure of treatment of pneumonia associated with highly resistant pneumococci in a child. Clin Infect Dis 1999; 29: $462-463$.

19. Daum RS, Nachman JP, Leitch CD, Tenover FC. Nosocomial epiglottitis associated with penicillinand cephalosporin-resistant Streptococcus pneumoniae bacteremia. J Clin Microbiol 1994; 32: 246-248.

20. Chesney PJ, Davis Y, English BK, Wang WC. Occurrence of Streptococcus pneumoniae meningitis during vancomycin and cefotaxime therapy of septicemia in a patient with sickle cell disease. Pediatr Infect Dis $J$ 1995; 14: 1013-1015.

21. Turett GS, Blum S, Fazal BA, Justman JE, Telzak EE. Penicillin resistance and other predictors of mortality in pneumococcal bacteremia in a population with high human immunodeficiency virus seroprevalence. Clin Infect Dis 1999; 29: 321-327.

22. Feikin DR, Schuchat A, Kolczak M, et al. Mortality from invasive pneumococcal pneumonia in the era of antibiotic resistance, 1995-1997. Am J Public Health 2000; 90: 223-229.

23. Metlay JP, Hofmann J, Cetron MS, et al. Impact of penicillin susceptibility on medical outcomes for adult patients with bacteremic pneumococcal pneumonia. Clin Infect Dis 2000; 30: 520-528.

24. Moroney JF, Fiore AE, Harrison LH, et al. Clinical outcomes of bacteremic pneumococcal pneumonia in the era of antibiotic resistance. Clin Infect Dis 2001; 33: 797-805.

25. Deeks SL, Palacio R, Ruvinsky R, et al. Risk factors and course of illness among children with invasive penicillin-resistant Streptococcus pneumoniae. The Streptococcus pneumoniae Working Group. Pediatrics 1999; 103: 409-413.

26. Pallares R, Capdevila $\mathrm{O}$, Linares $\mathrm{J}$, et al. Clinical relevance of current NCCLS ceftriaxone/cefotaxime resistance breakpoints in non-meningeal pneumococcal infections. Abstract book for 41st Annual ICAAC. Abstract L 903. Washington DC, USA, American Society for Microbiology, 2001; p. 460.

27. Rieux V, Carbon C, Azoulay-Dupuis E. Complex relationship between acquisition of beta-lactam resistance and loss of virulence in Streptococcus pneumoniae. J Infect Dis 2001; 184: 66-72.

28. Klugman KP, Koornhof HJ, Kuhnle V, Miller SD, Ginsburg PJ, Mauff AC. Meningitis and pneumonia due to novel multiply resistant pneumococci. $B M J$ 1986; 292: 730 .

29. Sanchez C, Armengol R, Lite J, Mir I, Garau J. Penicillin-resistant pneumococci and communityacquired pneumonia. Lancet 1992; 339: 988.

30. Lonks JR, Medeiros AA. High rate of erythromycin and clarithromycin resistance among Streptococcus pneumoniae isolates from blood cultures from
Providence, R.I. Antimicrob Agents Chemother 1993; 37: 1742-1745.

31. Waterer GW, Wunderink RG, Jones CB. Fatal pneumococcal pneumonia attributed to macrolide resistance and azithromycin monotherapy. Chest 2000; 118 : 1839-1840.

32. Fogarty C, Goldschmidt R, Bush K. Bacteremic pneumonia due to multidrug-resistant pneumococci in 3 patients treated unsuccessfully with azithromycin and successfully with levofloxacin. Clin Infect Dis 2000; 31: 613-615.

33. Kelley MA, Weber DJ, Gilligan P, Cohen MS. Breakthrough pneumococcal bacteremia in patients being treated with azithromycin and clarithromycin. Clin Infect Dis 2000; 31: 1008-1011.

34. Garau J. The hidden impact of antibacterial resistance in respiratory tract infection. Clinical failures: the tip of the iceberg? Respir Med 2001; 95: Suppl. A, S5-S11. and S26-S27.

35. McGee L, Klugman KP, Wasas A, Capper T, Brink A. Serotype $19 \mathrm{f}$ multiresistant pneumococcal clone harboring two erythromycin resistance determinants (erm(B) and mef(A)) in South Africa. Antimicrob Agents Chemother 2001; 45: 1595-1598.

36. Straus WL, Qazi SA, Kundi Z, Nomani NK, Schwartz B. Antimicrobial resistance and clinical effectiveness of co-trimoxazole versus amoxycillin for pneumonia among children in Pakistan: randomised controlled trial. Pakistan Co-trimoxazole Study Group. Lancet 1998; 352: 270-274.

37. Madhi SA, Madhi A, Petersen K, Khoosal M, Klugman KP. Impact of human immunodeficiency virus type 1 infection on the epidemiology and outcome of bacterial meningitis in South African children. Intern J Infect Dis 2001; 5: 119-125.

38. Perez-Trallero E, Garcia-Arenzana JM, Jimenez JA, Peris A. Therapeutic failure and selection of resistance to quinolones in a case of pneumococcal pneumonia treated with ciprofloxacin. Eur J Clin Microbiol Infect Dis 1990; 9: 905-906.

39. Urban C, Rahman N, Zhao X, et al. Fluoroquinoloneresistant Streptococcus pneumoniae associated with levofloxacin therapy. J Infect Dis 2001; 184: 794-798.

40. Davidson R, DeAzavedo J, Bast D, et al. Levofloxacin treatment failure of pneumococcal pneumonia and development of resistance during therapy. Abstracts of the 40th Interscience Congress of Antimicrobial Agents and Chemotherapy. Abstract 2103. Washington DC, USA, American Society for Microbiology, 2000; p. 127.

41. Kuehnert MJ, Nolte FS, Perlino CA. Fluoroquinolone resistance in Streptococcus pneumoniae. Ann Intern Med 1999; 131: 312-313.

42. Ho PL, Tse WS, Tsang KW, et al. Risk factors for acquisition of levofloxacin-resistant Streptococcus pneumoniae: a case-control study. Clin Infect Dis 2001; 32: 701-707.

43. Empey PE, Jennings HR, Thornton AC, Rapp RP, Evans ME. Levofloxacin failure in a patient with pneumococcal pneumonia. Ann Pharmacother 2001; 35: 687-690.

44. Ho PL, Que TL, Tsang DN, Ng TK, Chow KH, Seto WH. Emergence of fluoroquinolone resistance among multiply resistant strains of Streptococcus pneumoniae in Hong Kong. Antimicrob Agents Chemother 1999; 43: 1310-1313. 